This item was submitted to Loughborough's Research Repository by the author.

Items in Figshare are protected by copyright, with all rights reserved, unless otherwise indicated.

\title{
Grafted zeolites for the removal of metal cations from crude oil hydrotreatment extract
}

PLEASE CITE THE PUBLISHED VERSION

https://doi.org/10.5004/dwt.2019.23881

PUBLISHER

(C) Desalination Publications

VERSION

AM (Accepted Manuscript)

\section{PUBLISHER STATEMENT}

This work is made available according to the conditions of the Creative Commons Attribution-NonCommercialNoDerivatives 4.0 International (CC BY-NC-ND 4.0) licence. Full details of this licence are available at: https://creativecommons.org/licenses/by-nc-nd/4.0/

\section{LICENCE}

CC BY-NC-ND 4.0

\section{REPOSITORY RECORD}

Kukwa, R.E., and Sandie Dann. 2019. "Grafted Zeolites for the Removal of Metal Cations from Crude Oil Hydrotreatment Extract”. figshare. https://hdl.handle.net/2134/36885. 


\title{
Grafted zeolites for the removal of metal cations from crude oil hydrotreatment extract
}

\author{
R. E. Kukwa ${ }^{\mathrm{a}}$ *S.E. Dann ${ }^{\mathrm{b}}$
}

${ }^{a}$ Department of Chemistry, Benue State University, Makurdi, Benue State- Nigeria

Email: erdoorr@yahoo.com

Phone number: +448123287224

${ }^{\mathrm{b}}$ Department of Chemistry, Loughborough University, Loughborough, Leicestershire UK

Email: S.E.Dann@1boro.ac.uk

Phone number: +441509222568

\begin{abstract}
Surface-modified zeolite $\mathrm{Y}$ has been synthesised and studied for potential application as an adsorbent for the removal of metal cations from aqueous solutions. Zeolite $\mathrm{Y}$ was synthesised under hydrothermal conditions at $100{ }^{\circ} \mathrm{C}$ in an autoclave and characterised by elemental analysis and thermogravimetric analysis to determine the chemical formula of the host material as $\mathrm{Na}_{54.91} \mathrm{Al}_{56} \mathrm{Si}_{136} \mathrm{O}_{384} .246 .5 \mathrm{H}_{2} \mathrm{O}$. 3-Aminopropyltriethoxysilane (APTES) grafted zeolite $\mathrm{Y}$ was prepared by first preparing protonexchanged zeolite $\mathrm{Y}$ using an $0.1 \mathrm{M}$ ammonium nitrate solution followed by calcination at $350^{\circ} \mathrm{C}$. The APTES ligand was then grafted onto the protonated zeolite using three different solvent media. CHN analysis, FTIR spectroscopy, SSNMR and TG analysis indicated that the ligand was bonded covalently to zeolite $\mathrm{Y}$ attaching onto the inorganic surface through the available silanol groups. CHN analysis showed that hexane was the most effective solvent for carrying out ligand grafting, as indicated by the highest proportion of carbon present in the product after removal of free solvent (5.08\%). APTES grafted zeolite $\mathrm{Y}$ was exposed to aqueous solutions containing different concentrations of divalent nickel cations $(0.01 \mathrm{M}$ to $0.1 \mathrm{M})$. An increase to $73.8 \% \mathrm{Ni}$ (II) removal compared to $18.1 \%$ uptake by the parent zeolite $\mathrm{Y}$ without any graft was observed when the concentration of nickel was $0.01 \mathrm{M}$. The selectivity study using a solution containing five different transition metal cations; $\mathrm{Ni}$ (II), V (IV), $\mathrm{Cu}$ (II), Zn (II), and Fe (II) to mimic the species most often observed in hydrotreatment extract from crude oil, showed proportional removals of $83.7 \%, 91.3 \%, 82.8 \%, 70.6 \%$ and $85.7 \%$ respectively. This study indicates that APTES modified zeolite Y could be a useful material for the removal of catalytic poisons in hydroprocessing solutions during the processing of heavier crude oils.
\end{abstract}

Keywords: Zeolite Y, ligand, (3- aminopropyl) triethoxysilane, metal cations, crude oil 


\section{Introduction}

Various human activities such as industrial works, burning of fossil fuels and hydrotreating of heavy crude oil amongst other anthropogenic activities are found to be responsible for release of metal cations into the environment beyond permissible levels [1]. Heavy crude oil contains higher proportions of impurities such as sulfur and asphaltenes (including occluded metal cations) than lighter crude oil which makes the processing of the heavier crude oils more difficult and thus the oil itself less desirable [2]. These impurities, in addition to polluting the crude oil, also present a disposal problem to the environment. Current methods used for the removal of asphaltenes and their associated metal cations to upgrade and lighten the crude oil include distillation, solvent refining and hydrotreating processes. The conventional hydrotreating processes use catalysts and hydrogen to facilitate the refining process and increase the value of the oil by reducing the viscosity and removing the impurities [2]. The catalysts, which are the major active components of the process, can be poisoned by the metal cations that are released when the asphaltenes in the crude oil break down. The poisoning process is a result of the irreversible binding of cations such as nickel (II) and vanadium (IV) to the catalysts which gradually reduce their efficacy. In order to prolong the life span of the catalysts, removal of the metal cations from the crude oil extract is necessary before the ions come into contact with the active materials [2]. The scale of the refining process means that this removal process has to be simple, cost effective and generate minimal waste during its operation [2]. The harmful and damaging effects of these metal cations in aqueous systems as well as their release from heavier crude oil during hydroprocessing has prompted the need to search for materials that can effectively and safely remove these cations.

Zeolitic materials, due to their porous frameworks, high surface areas and good thermal stability are utilized in many industrial applications such as heterogeneous catalysis, separation and environmental remediation. The ion exchange capability that leads to water softening for detergents through exchange of hard water ions such as $\mathrm{Ca}^{2+}$ with exchangeable $\mathrm{Na}^{+}$cations inside the zeolite could theoretically be utilized for the removal of transition metal cations from the hydroprocessing solutions before they can poison the active catalysts. Zeolites are characterized by highly porous structural textures that are based upon frameworks that are constructed from $\mathrm{TO}_{4}$ tetrahedra, where $\mathrm{T}=$ $\mathrm{Si}$ or Al. These tetrahedra are joined together through their oxygen atoms to form subunits such as rings and cages. The subunits then join together form lattices by repeating identical building blocks [3-4].

The composition of a zeolite can be represented by the general formula given in Equation 1

Comp. of a Zeolite $=m / x^{x+}\left[\left(\mathrm{SiO}_{2}\right)_{n}\left(\mathrm{AlO}_{2}\right)_{m}\right] \cdot{ }_{y} \mathrm{H}_{2} \mathrm{O}$

The Si/Al ratio has a large effect on the ion exchange capacity of a given zeolite as it controls the number of exchangeable cations within the pores in the framework. If no aluminium is present in the framework, the framework will be neutral and there are no cations inside the framework to exchange. 
The lower the $\mathrm{Si} / \mathrm{Al}$ ratio, the higher the charge imbalance on the framework and the more $\mathrm{M}^{+}$counter ions must be available to counter balance the excess charge on the framework. This arises from the isomorphous substitution of $\mathrm{Al}^{3+}$ for $\mathrm{Si}^{4+}$ in the framework of vertex-linked tetrahedra generating a negative charge for each silicon cation replaced. This negative charge is compensated by the cations that are present during synthesis and held in the interstices of the structure on crystallization [5]. Thus, in theory, a large factor of the effectiveness of a zeolite as an ion exchanger is a low Si/Al ratio. Zeolites such as zeolite $\mathrm{Y}$ and $\mathrm{ZSM}-5$ with high $\mathrm{Si} / \mathrm{Al}$ ratios are not considered as excellent ion exchangers due to the small number of exchangeable cations, however they have the ability to additionally act as inorganic supports due to their high silanol group concentration, good porosity and large surface area [6-10]. In their protonic forms they are able to make available high concentration of surface hydroxyl groups that can serve as adsorption sites [11-12]. These zeolites can thus be used as inorganic supports to attach organic ligands which can then be used for the irreversible immobilization of metal cations through coordination of these cations to the donor atoms on the organic ligands. Nitrogen- and sulfurcontaining ligands which are known to demonstrate high selectivity towards heavy metal ions when attached on zeolites surfaces, are able to immobilize the metal cations from solution without the need for waste processing and disposal [13-14]. This means surface modified zeolites can immobilise cations not only by ion exchange and electrostatic interaction of the cations within the negatively charged framework, but also by coordination of cations to the donor groups on the ligands grafted onto their surface.

Zeolites and clays are low cost materials and are considered environmentally benign since they are capable of breaking down to natural materials such as quartz and feldspars on decomposition. Exchanged materials can also be easily recycled for the original application by flooding with a solution concentrated in the cations (normally sodium) [2] which were exchanged. Many different natural and synthetic zeolitic materials have been used to remove species which are harmful or damaging to industrial processes such as the natural zeolite, clinoptilolite, for removal of caesium and strontium in the SIXEP effluent plant at Sellafield or the synthetic zeolite, Linde 4A, used in washing powder [15$16]$.

Surface functionalization of ordered porous inorganic materials has attracted interest as a result of their use as supports for organic grafts to create inorganic/organic composite materials for various purposes [17-22]. Modified mesoporous materials such as the ligand grafted clay mineral composites, silica and cellulose have been successfully used to selectively immobilise metal cations from solutions of their salts [17-22].

Although much work has been reported previously on functionalizing mesoporous materials, where the aim has been to maximise the surface functionalization through surface roughening via chemical/physical treatment, less attention has been given to analogous studies on the related microporous materials; the zeolites. Comparable studies, using zeolites with high $\mathrm{Si} / \mathrm{Al}$ ratios such as zeolite $\mathrm{Y}$, where attempts to modify the materials surface with grafting agents to improve metal cation 
uptake capabilities in relation to the pure zeolite host are rare as the surface area available for modification is low, inherently meaning that the available sites for modification is also low. However, this study concentrates on low concentrations of species in aqueous media where high uptake capability is less important than the stability of the grafting host in the water medium. Using zeolite $\mathrm{Y}$, a common zeolite used extensively in the petrochemical industry and the common ligand APTES (3aminopropylsilane) as a graft, a composite sequestering agent for removal of harmful cations from hydroprocessing water is prepared. APTES was chosen as a flexible ligand as there are various published studies which describe both the efficacy and stability of APTES grafted supports for the removal of different ions in different environments [23-24]. This study describes experiments to maximise the loading of APTES on zeolite Y using different solvent media, the effectiveness of using the modified zeolite $\mathrm{Y}$ in removing nickel (II) cations from solution as compared with the parent zeolite $\mathrm{Y}$ and contrasts the differences in removal of five transition metal cations from a mixture of species in hydrotreatment extract.

\section{Experimental}

\subsection{Materials}

Zeolite $\mathrm{Y}(\mathrm{Si} / \mathrm{Al}=2.6)$ and surface modified zeolite $\mathrm{Y}$ were synthesized and characterized, heavy crude oil with significant impurities levels was obtained from SNEPCO. 3aminopropyltriethoxysilane, $\mathrm{Ni}\left(\mathrm{NO}_{3}\right)_{2} .6 \mathrm{H}_{2} \mathrm{O}, \mathrm{Cu}\left(\mathrm{NO}_{3}\right)_{2} .5 \mathrm{H}_{2} \mathrm{O}, \quad \mathrm{VOSO}_{4} .4 \mathrm{H}_{2} \mathrm{O}, \quad \mathrm{ZnSO}_{4} .7 \mathrm{H}_{2} \mathrm{O}$ and $\mathrm{FeCl}_{2} \cdot 4 \mathrm{H}_{2} \mathrm{O}$ were all purchased from Sigma Aldrich, UK.

\subsection{Synthesis of zeolite $Y$}

Zeolite Y was synthesised following the method described by Ginter, Bell and Radke [25]. The batch compositions for the synthesis are given by; seed gel (5\% of $\mathrm{Al}): 10.67 \mathrm{Na}_{2} \mathrm{O}: \mathrm{Al}_{2} \mathrm{O}_{3}: 10 \mathrm{SiO}_{2}$ $: 180 \mathrm{H}_{2} \mathrm{O}$; Feedstock gel (95\% of $\left.\mathrm{Al}\right): 4.30 \mathrm{Na}_{2} \mathrm{O}: \mathrm{Al}_{2} \mathrm{O}_{3}: 10 \mathrm{SiO}_{2}: 180 \mathrm{H}_{2} \mathrm{O}$; Overall gel: $4.62 \mathrm{Na}_{2} \mathrm{O}$ : $\mathrm{Al}_{2} \mathrm{O}_{3}: 10 \mathrm{SiO}_{2}: 180 \mathrm{H}_{2} \mathrm{O}$. The seed gel was prepared by mixing $19.95 \mathrm{~g}$ water, $4.07 \mathrm{~g} \mathrm{NaOH}$ and $2.09 \mathrm{~g}$ sodium aluminate with continuous stirring in a $50 \mathrm{~mL}$ conical flask until dissolved. The solution was added to $22.72 \mathrm{~g}$ sodium silicate solution, stirred for $10 \mathrm{~min}$ and allowed to age at room temperature for a day. Similarly, the feedstock was also prepared by mixing $130.97 \mathrm{~g}$ water, $0.14 \mathrm{~g} \mathrm{NaOH}$ and $13.09 \mathrm{~g}$ sodium aluminate solution with continuous agitation in a $500 \mathrm{~mL}$ beaker until dissolved. The solution was then added to $142.43 \mathrm{~g}$ sodium silicate solution and stirred vigorously until the gel appeared smooth. The seed gel prepared was then slowly added to the feedstock under vigorous stirring for 20 $\mathrm{min}$. The overall gel was finally transferred into $200 \mathrm{~mL}$ capacity Parr digestion bombs and crystallised 
at $100{ }^{\circ} \mathrm{C}$ for $7 \mathrm{~h}$. The wet solid product was filtered under vacuum, washed with deionised water until the $\mathrm{pH}$ of filtrate was below 9 and dried at $100{ }^{\circ} \mathrm{C}$ overnight. The product was then characterised.

\subsection{Synthesis of the ligand attached zeolites}

The ligand attachment on the as-synthesized zeolite $\mathrm{Y}$ was carried out as shown by the schematic diagram in figure 1 . The ligand grafting was carried out in three different solvents (hexane, toluene and acetone) following the procedure described in the literature [26] with slight changes in reaction conditions. $5 \mathrm{~g}$ of zeolite $\mathrm{Y}$ was converted into the protonic form by exchanging with $0.1 \mathrm{M}$ $\mathrm{NH}_{4} \mathrm{NO}_{3}$ solution and heating the product at $350{ }^{\circ} \mathrm{C}$ to drive off $\mathrm{NH}_{3}$ leaving behind $\mathrm{H}^{+}$. Exactly $2.5 \mathrm{~g}$ $\left(1.455 \times 10^{-4}\right.$ moles) of the protonic zeolite $\mathrm{Y}$ was suspended in $40 \mathrm{~mL}$ of the appropriate solvent in a round bottom flask and stirred under reflux for $1 \mathrm{~h}$ at $40^{\circ} \mathrm{C} .6 \mathrm{~mL}\left(2.568 \times 10^{-2} \mathrm{moles}\right)$ of APTES was added drop wise to the mixture under stirring using a dropping pipette. The mixture was then refluxed for $24 \mathrm{~h}$ at $40^{\circ} \mathrm{C}$. Once the reaction was complete, the functionalized zeolite $\mathrm{Y}$ was filtered, washed with the appropriate solvent followed by distilled water and dried at $80^{\circ} \mathrm{C}$ overnight.

\subsection{Characterization}

The as-synthesized and the ligand grafted zeolite $\mathrm{Y}$ were characterized by PXRD, FTIR, SEMEDS, CHN, thermogravimetric analysis (TGA) and solid-state NMR.

The CHN data were collected on an Exeter analytical ink (EAI) CE-440 elemental analyzer to determine the extent of the ligand grafted.

The powder X-ray Diffraction data of the zeolites were collected on a Bruker D8 Advance. The PXRD data were collected using $\mathrm{Cu} \mathrm{K} \alpha_{1}(1.5406 \AA)$ radiation, over $2 \theta$ range between $5-60^{\circ}$ using a step size of $0.022^{\circ}$ and step time of 178 s for 43 minutes.

Solid-state NMR spectra were recorded on Bruker Avance 500MHz NMR spectrometer, equipped with a $4 \mathrm{~mm}$ MAS HX probe, $100 \mathrm{~W}$ proton amplifier and $500 \mathrm{~W} \mathrm{X}$ amplifier. Crosspolarisation used a ${ }^{1} \mathrm{H}$ pulse of 2 us (at $-5.5 \mathrm{~dB}$ ), a ramped proton CP pulse of $2 \mathrm{~ms}$ (at $-4.0 \mathrm{~dB}$ ) and a carbon $\mathrm{CP}$ pulse of $2 \mathrm{~ms}$ (at $-3.1 \mathrm{~dB}$ ). ${ }^{1} \mathrm{H} \rightarrow{ }^{29} \mathrm{Si}$ and ${ }^{13} \mathrm{C}$ cross-polarization (CP)/MAS NMR experiments were carried out to selectively enhance the signals of $\mathrm{Si}$ and $\mathrm{C}$ atoms strongly when attached via hydroxyl groups to the surface. TPPM15 proton decoupling was applied during the $30 \mathrm{~ms}$ acquisition time. FIDs contain $3 \mathrm{k}$ data points which were Fourier transformed into 16k data points; an exponential function of $20 \mathrm{~Hz}$ was applied to the FID using Bruker TOPSPIN (1.3) software. Spectra were referenced to external TMS $\left({ }^{1} \mathrm{H},{ }^{13} \mathrm{C},{ }^{29} \mathrm{Si}\right)$ and the magic angle was set up using $\mathrm{KBr}$. Magic angle spinning of $10 \mathrm{kHz}$ was used. CP-MAS ${ }^{29} \mathrm{Si}$ used a relaxation delay of $5 \mathrm{~s}$ between each scan; DP-MAS ${ }^{29} \mathrm{Si}$ used a relaxation of $10 \mathrm{~s}$. Direct polarisation was used for ${ }^{1} \mathrm{H}$ and ${ }^{27} \mathrm{Al}$ spectra (4 us at $1 \mathrm{~dB}$ ). 
The infra-red spectrum of the as-synthesised zeolite sample was obtained using a Perkin-Elmer Paragon 1000 FT-IR spectrophotometer over the IR region 400-1400 $\mathrm{cm}^{-1}$. Measurements for the ligand modified zeolite $\mathrm{Y}$ were carried out as a subtraction of that of the parent zeolite from the grafted zeolite over the IR region of $1000-4000 \mathrm{~cm}^{-1}$.

The thermal analysis of the zeolites after synthesis and ligand loading was carried out under the flow of nitrogen while monitoring the weight loss and thermal behaviour of the zeolites on a Q600 SDT V20.9 Build 20 thermogravimetric analyser. A small amount of sample (ca. $10 \mathrm{mg}$ ) was used for the analysis and an indium standard was used for the temperature calibration.

The SEM-EDS spectra were produced on an EDAX Phoenix, EDX with a Carl Zeiss 1530 VP Field Emission Gun Scanning Electron Microscope (FEG-SEM) microanalysis system. The samples were sprinkled onto $12 \mathrm{~mm}$ aluminium stubs using "carbon sticky tabs". These were then gold coated using an Emitech SC 7640 gold/palladium sputter coater to reduce the static charges during the analysis.

\subsection{Extraction of trace metal ions from crude oil}

Water $\left(\mathrm{H}_{2} \mathrm{O}\right), 99 \%$ isopropyl alcohol $\left[\mathrm{CH}_{3} \mathrm{CHOHCH}_{3}\right.$ (IPA)], 0.05M EDTA or $0.05 \mathrm{M} \mathrm{H}_{3} \mathrm{PO}_{4}$ were used to extract metal cations from crude oil. $50 \mathrm{~mL}$ crude oil was measured into a round bottom flask containing $100 \mathrm{~mL} \mathrm{H}_{2} \mathrm{O}$ and refluxed for $24 \mathrm{~h}$ at $110^{\circ} \mathrm{C}$. The mixture was then transferred into a $250 \mathrm{~mL}$ separating funnel and left standing overnight. Distinct layers were carefully separated; the organic layer was ashed for XRF analysis and the solution was analysed by ICP. The same procedure was repeated for aqueous solutions of $\mathrm{H}_{3} \mathrm{PO}_{4}$ and EDTA. A ratio of 1:1 for $\mathrm{CH}_{3} \mathrm{CHOHCH}_{3}$ (IPA) and water was used in the case of IPA and the rest of the procedure remained the same.

\subsection{Uptake behaviour of metal cations by modified and unmodified zeolite $Y$}

Following completion of the grafting experiments, the efficacy of APTES modified zeolite Y for removing nickel (II) cations from solution was examined; nickel (II) has been shown to consistently be the most abundant and catalyst-damaging impurity present in crude oil of all the metal species detected. Nickel (II) ions uptake by the modified and unmodified zeolite Y was investigated by immersing $0.5 \mathrm{~g}$ of the parent and modified zeolite with excess solutions of nickel (II) ions at three different concentrations $(0.01 \mathrm{M}, 0.05 \mathrm{M}$, and $0.1 \mathrm{M})$. The mixture was left to equilibrate at room temperature $\left(18^{\circ} \mathrm{C}\right)$ on a roller mixer for $24 \mathrm{~h}$ and the resultant zeolitic products were filtered and washed with distilled water after $24 \mathrm{~h}$ of equilibration. The zeolite materials were then dried overnight at $80^{\circ} \mathrm{C}$. Characterisation of the solid product was carried out using PXRD to examine any changes to the structure, while the concentration of nickel cations remaining in solution were determined by ICPOES.

A similar procedure was carried out for a solution containing a mixture of five metal cations $\mathrm{Ni}$ (II), V (IV), Zn (II), Cu (II) and Fe (II) as described in literature by Keane et al [27]. $10 \mathrm{~mL}$ of $0.05 \mathrm{M}$ 
solutions each of $\mathrm{Ni}$ (II), V (IV), Zn (II), Cu (II) and Fe (II) were measured into polyethylene bottles containing $0.5 \mathrm{~g}$ each of the modified zeolite $\mathrm{Y}$ and left to equilibrate at room temperature on the roller mixer for $24 \mathrm{~h}$. This process was carried out in triplicate. The mixture was filtered after equilibration for $24 \mathrm{~h}$, washed and dried overnight at $80^{\circ} \mathrm{C}$. The crystallinity of the solid product and the amounts of cations remaining in solution were determined by PXRD and ICP-OES respectively.

\section{Results and discussion}

\subsection{Synthesis of zeolite $Y$}

\subsubsection{PXRD}

The PXRD data from the zeolite Y product matched against the ICDD database pattern (01-704285) for zeolite Y phase is shown in Figure 2. The PXRD pattern for the zeolite shows that the material crystallised as a single phase with good crystallinity as shown by the excellent match between the ICDD database pattern and the sharp reflections seen in the experimental data. No unmatched reflections were observed, indicating a pure product. The low background on the data suggests that minimal amorphous/poorly crystalline material is present. The formula of the product was determined using elemental analysis (Table 1) and the number of water molecules in the product by thermogravimetric analysis; vide infra.

\subsubsection{FTIR}

FTIR results for the synthesised zeolite showed that the syntheses formed the targeted zeolite $\mathrm{Y}$ (Figure 3). A broad band was observed in the region $1019 \mathrm{~cm}^{-1}$ which was attributed to the asymmetric vibrations of Si-O bridging and $\mathrm{Si}-\mathrm{O}$ non-bridging bonds. The band in the range $717 \mathrm{~cm}^{-1}$ was due to the symmetric stretching of internal vibrations while the internal vibrations due to the bending of the T-O tetrahedra occurred at $455 \mathrm{~cm}^{-1}$. Vibrations of the double six rings (D6R) connecting the sodalite cages occurred around $579 \mathrm{~cm}^{-1}$ while that around $666 \mathrm{~cm}^{-1}$ was assigned to the symmetric stretching of external T-O linkages in the zeolite. The band at $1150 \mathrm{~cm}^{-1}$ was attributed to the asymmetric stretching of external T-O linkages in the zeolite respectively [28].

\subsubsection{TGA}

The percentage weight loss for the parent zeolite $\mathrm{Y}$ by thermogravimetric analysis reveals the loss of water in a single temperature range $20-300^{\circ} \mathrm{C}$ (Figure 4). The thermogravimetric analysis for zeolite Y generated a calculated water loss of 246.5 moles per formula unit

\subsubsection{SEM-EDS}

The energy dispersive $\mathrm{X}$-ray spectroscopy analysis of the as synthesised zeolite $\mathrm{Y}$ was carried out to determine the elemental composition of the zeolite. From the elemental composition, the Si/Al 
ratio of the zeolite calculated was 2.6. Table 1 shows the elemental composition as determined by the EDS and the $\mathrm{Si} / \mathrm{Al}$ ratios of the zeolite.

\subsection{Ligand attachment on zeolite surfaces}

\subsubsection{Elemental analysis}

The CHN analysis of the grafted zeolite $\mathrm{Y}$ showed the highest loading of the ligand on the zeolite in hexane, closely followed by toluene. The ligand loading for acetone was significantly lower (Table 2). This indicates that solvent polarity plays an important role in the successful grafting of ligands on the zeolite host. Less polar solvents appear more effective at attaching the APTES to the host. This is in full agreement with previous studies on APTES which indicates that APTES is strongly affected by ionising solvents during the grafting stage $[26,30]$. The higher $\% \mathrm{C}, \% \mathrm{H}$ and $\% \mathrm{~N}$ indicates that ligand attachment on the zeolite Y had occurred.

\subsubsection{PXRD}

PXRD data of the grafted zeolite $\mathrm{Y}$ did not differ significantly from that of the parent zeolite $\mathrm{Y}$ (Figure 2). This could be due to the small amount of ligand loading on the zeolite meaning that there is no ordered long-range structure associated with the low level of graft. No additional crystalline impurities were formed on grafting and there was not a significant change in background after grafting; this implies that the framework was stable to grafting and did not break down to form amorphous material. The only phase observed in the PXRD pattern was that for crystalline zeolite Y. The data compared against the ICDD database for the theoretical phases (01-070-4285, Na54.91 $\mathrm{Al}_{56} \mathrm{Si}_{136} \mathrm{O}_{384}$. $246.5 \mathrm{H}_{2} \mathrm{O}$ ) clearly suggest that the zeolite framework structure is kept intact after the modification. This is in good agreement with earlier investigations into the preparation of surface functionalised framework materials $[26,30]$.

\subsubsection{Solid state NMR}

The ${ }^{29} \mathrm{Si} \mathrm{MAS} \mathrm{NMR} \mathrm{spectrum} \mathrm{of} \mathrm{the} \mathrm{ligand} \mathrm{grafted} \mathrm{zeolite} \mathrm{Y}$ is shown in Figure 5 . The ${ }^{29} \mathrm{Si}$ MAS NMR spectra of zeolitic materials shows up to five resonances $(-105)-(-107)=\mathrm{Q}^{4},(-95)-(-105)=$ $\mathrm{Q}^{3},(-88)-(-95)=\mathrm{Q}^{2},(-86)-(-92)=\mathrm{Q}^{1},(-80)-(-86)=\mathrm{Q}^{0}$ depending on the silicon environment; $\mathrm{Q}^{4}$ represents a silicon tetrahedron surrounded by four other silicon tetrahedra whereas for $\mathrm{Q}^{0}$, all the silicon tetrahedra have been replaced by aluminium tetrahedra [31-33]. The cross polarisation (CP) spectrum for zeolite $\mathrm{Y}$ following the grafting (Figure 5) clearly shows additional signals at about -50 and -60 besides in addition to signals at $\mathrm{Q}^{1}, \mathrm{Q}^{2}, \mathrm{Q}^{3}$ and $\mathrm{Q}^{4}$. The additional signals correspond to $\mathrm{T}^{2}=$ $\left[\mathrm{Si}(\mathrm{OSi})_{2}(\mathrm{OH}) \mathrm{R}\right]$ and $\mathrm{T}^{3}=\left[\mathrm{Si}(\mathrm{OSi})_{3} \mathrm{R}\right]$ where $\mathrm{R}=\left(\mathrm{CH}_{2}\right)_{3} \mathrm{NH}_{2}$ [32-34]. The signal with the highest intensity $\left(\mathrm{T}^{3}\right)$ is an indication that most of the ligand molecules are covalently bonded to the zeolite $\mathrm{Y}$ 
by tridentate bonds (figure 1c). This result is in good agreement with earlier studies on inorganicorganic hybrids between this ligand and vermiculite [34].

The ${ }^{13} \mathrm{C}$ CP/MAS NMR spectrum for the ligand loaded zeolite $\mathrm{Y}$ is presented in Figure 6. The $\mathrm{CP} / \mathrm{MAS}$ NMR spectrum for zeolite $\mathrm{Y}$ gave broad peaks at $9 \mathrm{ppm}, 23 \mathrm{ppm}$ and $44 \mathrm{ppm}$ which can be attributed to propyl spacer chain [35-36], again suggesting that there has been some surface modification which is due to the ligand grafting.

\subsubsection{FTIR}

The infrared spectroscopy studies of the grafted zeolite showed good evidence of successful grafting of the ligand on zeolite Y (Figure 7) as shown by the absorption bands typical of functional groups present in the ligand. The broad absorption band at $3491 \mathrm{~cm}^{-1}$ was attributed to the $\mathrm{OH}$ stretching modes of the surface water and silanol groups. The band at $1644 \mathrm{~cm}^{-1}$ was assigned to the angular vibration of the water bonded to the zeolite framework while the weak bands at $1384 \mathrm{~cm}^{-1}$ and $1476 \mathrm{~cm}^{-}$

${ }^{1}$ were assigned to $\mathrm{N}-\mathrm{C}$ and $\mathrm{N}-\mathrm{H}$ bonds corresponding to the amine group in the ligand, thus agreeing to the success of the ligand grafting in the final product.

\subsubsection{Thermal analysis}

The data from the TGA further supports the observations made from the solid-state NMR and FTIR. There was an observed weight loss for zeolite $\mathrm{Y}$ at two distinct temperatures in the profile (Figure 8) after the ligand grafting, whereas only a single weight loss at low temperature was observed before the graft (Figure 4). The two distinct weight losses for the modified zeolite Y suggest two different species are lost. The temperature at which the losses occur are appropriate for occluded water and the APTES ligand respectively. PXRD data of the thermally treated sample of the ligand attached zeolite $\mathrm{Y}$ showed that the zeolite framework remained intact at both $200^{\circ} \mathrm{C}$ and $400^{\circ} \mathrm{C}$ where the weight losses occurred in the TGA. These data indicate that the weight loss was not as a result of a phase change e.g. decomposition of the zeolite framework and the two weight losses at $200^{\circ} \mathrm{C}$ and $400^{\circ} \mathrm{C}$ are associated with the loss of occluded water and the ligand (APTES) respectively.

\subsection{Comparative uptake behaviour of metal cations by modified and unmodified Zeolite $Y$}

Analysis of the modified and unmodified zeolite $\mathrm{Y}$ and the sample solutions after treatment with nickel (II) at three different concentrations $(0.01 \mathrm{M}, 0.05 \mathrm{M}$, and $0.1 \mathrm{M})$ showed that Ni (II) was adsorbed by both the modified and unmodified zeolite Y (Figure 9). The nickel removal by modified zeolite Y (73.8\%) was however much higher than that by parent zeolite Y (18.1\%) under identical experimental conditions. An increase in the nickel (II) solution concentration lowered the affinity of the zeolite for the in-going nickel ions which is in good agreement with literature data [26]. This was a general trend observed for both the modified and unmodified zeolite Y. The marked increase in the uptake of nickel (II) for the modified zeolite Y could be attributed to the additional immobilization effect of the ligand (APTES) grafted on the zeolite. Data from these analyses showed that the metal 
loading on the grafted zeolite was higher than the ligand loading (Table 2) which agrees well with previous reports [22], where $\mathrm{Ni}$ (II) ion uptake has not only been immobilized by the ligand, but has also exchanged with counter-ions present in the zeolite.

Analysis of the modified zeolite $\mathrm{Y}$ after treatment with a mixture of metal cations Ni (II), V(IV), $\mathrm{Cu}$ (II), $\mathrm{Zn}$ (II) and $\mathrm{Fe}$ (II) to investigate the selective adsorption of these metals showed adsorption for all the metals tested (figure 10). In the experimental process, the uptake capacity of $\mathrm{Ni}$ (II) was $83.7 \%$ at $24 \mathrm{~h}$ contact, $\mathrm{V}(\mathrm{IV})$ was $91.3 \%$ at $48 \mathrm{~h}$ contact, $\mathrm{Cu}$ (II) was $82.8 \%$ at $48 \mathrm{~h}$ contact, $\mathrm{Zn}$ (II) was $70.6 \%$ at $48 \mathrm{~h}$ contact and Fe (II) was $85.7 \%$ at $48 \mathrm{~h}$ contact. The V (IV) and Fe (II) removal were observed to be higher than $\mathrm{Ni}$ (II) and $\mathrm{Cu}$ (II) while that for $\mathrm{Zn}$ (II) was much lower. This result suggests that $\mathrm{Fe}$ (II) could be a competing ion in the selective zeolitic removal of the $\mathrm{Ni}$ (II) and V(IV) from solution and hence from crude oil. The graph displayed in Figure 10 showed that time has very little or no effect on the adsorption of the metal ions by the modified zeolite Y. This result is in good agreement with recent work on the adsorption kinetic of nickel ions on $\mathrm{Fe}_{3} \mathrm{O}_{4} / \mathrm{CD}$ [37]. It was not possible to determine whether or not iron (II) was oxidized to iron (III) or vanadium (IV) was oxidized to vanadium (V) during the exchange process due to the complexity of this multicomponent system. However, of key importance is whether or not the ions can be removed from solution rather than what the oxidation state of the species is in the product. In the case of both iron and vanadium cations, both species are first row transition metals and according to hard/soft acid/base theory both Fe (II) and Fe (III) and V (IV) and $\mathrm{V}(\mathrm{V})$ will be coordinated by the APTES ligand (N/O donors).

\subsection{Extraction of trace metal ions from crude oil}

Nickel, iron and zinc cations were the three trace metal species extracted in the highest concentration from the crude oil. This is an expected outcome, because they were the most abundant metal ions found in the ashed crude oil analysis by ICP analysis. The results of the extraction of trace metal ions from crude oil is as shown in table 4 . The results show that all the metal ions could be extracted by the solvents and aqueous solutions used. The degree of extraction of metal cations however varies according to the following series in order of increasing \% extraction; $\mathrm{H}_{2} \mathrm{O}<\mathrm{H}_{3} \mathrm{PO}_{4}<$ EDTA $<$ IPA, except for $\mathrm{Fe}^{2+}$ where the extraction in $\mathrm{H}_{3} \mathrm{PO}_{4}$ is higher than that in EDTA. The amounts of cations extracted by IPA as compared to the other extracting media, shows the alcohol could serve as an extracting medium for the zeolitic removal of metal cations from crude oil.

\section{Conclusion}

The present study demonstrates the efficacy of modified zeolite $\mathrm{Y}$ for the removal of metal ions from solution and hence from hydroprocessing concentrate derived from crude oil. APTES grafted zeolite Y was prepared and characterized using CHN, NMR, PXRD and IR. Successful ligand grafting was achieved for zeolite Y. Adsorption studies of the grafted zeolite Y using nickel (II) solution showed 
the grafted zeolite Y gave higher nickel (II) removal efficiency (73.8\%) compared to the parent zeolite Y (18.1\%).

\section{Acknowledgements}

We would like to acknowledge the Chemistry Department, Loughborough University, Loughborough where this work was done (Thesis), we also acknowledge the PTDF, TETF and the Benue State University, Nigeria, for funding. A special thank you to Dr. Sandie Dann for effective supervision of the work, Dr. M. Edgar, D.T. Kukwa and Hannah Ikyereve for all their support.

\section{References}

[1] B.J. Alloway and D.C. Ayres. Chemical principles of environmental pollution. Chapman and Hall, Oxford, (Ed.), 1981.

[2] R.E. Ikyereve. Investigations into the pretreatment methods for the removal of nickel (II) and vanadium (IV) from Crude Oil. PhD Thesis, Loughborough University, Loughborough, 2014.

[3] R.M. Barrer. Zeolites and their synthesis. Zeolites 1981, 1, 130-140.

[4] J.B. Nagy, P. Bodart, I. Hannus and I. Kiricsi. Synthesis, characterization and use of zeolitic microporous materials. DecaGen Publishers Ltd, Szeged, Hungary, 1998.

[5] A. Dyer. An introduction to zeolite molecular sieves. Bath Press Ltd, Bath, 1988.

[6] R. Szostak. Molecular sieves, principles of synthesis and identification. Van Nostrand, Reinhold, New York, 1989.

[7] F.A. Mumpton and L.B Sand. A new industrial mineral commodity; natural zeolites: occurrence, properties, use. Pergamon Press, New York, USA, 1978.

[8] D.W. Breck. Zeolite molecular sieves, structure chemistry and use. Wiley, New York, USA, 1974.

[9] H. Van Bekkum, E.M. Flanigen, P.A. Jacobs and J.C. Jansen. Introduction to zeolite science and practice, studies in surface science and catalysis, Elsevier Science Publishers, Amsterdam, 2001.

[10] M.I. Occelli and H. Kessler. Synthesis of porous materials: zeolites, clays and nanostructures. CRC Press, New York, 1997.

[11] E. Erdem N. Karapinar and R. Donat. The removal of heavy metal cations by natural zeolites. J. Coll. Inter. Sci. 2004, 280, 309-314.

[12] P.W. Schindler, B. Furst, R. Dick and P.U. Wolf. Ligand properties of surface silanol group. I. surface complex formation with $\mathrm{Fe}^{2+}, \mathrm{Cu}^{2+}$ and $\mathrm{Pb}^{2+}$. J. Coll. Inter. Sci. 1976, 55, 469-475. 
[13] S.M. Evangelista, E. DeOliveira, G.R. Castro, L.F. Zara and A.G.S. Prado. Hexagonal mesoporous silica modified with 2- mercaptothiazoline for removing mercury from water solution. Surf. Sc., 2007, 601, 2194-2202.

[14] Y. Jiang, Q. Gao, H. Yu, Y. Chen and F. Deng. Intensively competitive adsorption for heavy metal ions by PAMAM-SBA-15 and EDTA-PAMAM-SBA-15 inorganic-organic hybrid materials, Micropor. Mesopor. Mater. 2007, 103, 316-324.

[15] R.M. Barrer. Zeolites and clay minerals as sorbents and molecular sieves. Academic Press, FRS, London, 1989.

[16] F. Helffrich. Ion-exchange, Dower Publications, New York, NY, 1995, 63-66.

[17] M. Addy, B. Losey, R. Mohseni, E. Zlotnikov, A. Vasiliev. Adsorption of heavy metal ions on mesoporous silica-modified montmorilonite containing a grafted chelate ligand, Applied Clay Sc. 2012, 59-60, 115-120.

[18] P. Tzvetkova and R. Nickolov. Modified and unmodified silica gel used for heavy metal ions removal from aqueous solution, J. Chem. Technol. Metall., 2012, 47(5), 498-504.

[19] Z. Hu, X. Zhang, D. Zhang, and JX Wang. Adsorption of $\mathrm{Cu}^{2+}$ on amine functionalized mesoporous silica bracket. J. Water Air Soil Pollut., 2012, 223, 2743-2749.

[20] O. Karnitz Junior, L.V.A. Gurgel, R.P. de Freitas and L.F. Gil. Adsorption of $\mathrm{Cu}^{2+}, \mathrm{Cd}^{2+}$ and $\mathrm{Pb}^{2+}$ from aqueous single metal solutions by mercerized cellulose and mercerized sugarcane bagasse chemically modified with EDTA dianhydride (EDTAD). J. Carbohydr. Polym. 2009, 77, 643-650.

[21] R. Guilet, N. Chiron and E. Deydier. Adsorption of $\mathrm{Cu}$ (II) and $\mathrm{Pb}$ (II) onto a grafted silica: Isotherms and kinetic models. J. Water Res. 2003, 37, 3079-3086.

[22] I. Hatay, R.Gup and M. Ersoz. Silica gel functionalized with 4-phenylacetophenone 4aminobenzyolhydrazone: Synthesis of a new chelating matrix and its application as metal ion collector. J. Hazard. Mater. 2008, 150, 546-553.

[23] A.N. Vasiliev, L.V. Golovko, V.V. Trachevsky, G.S. Hall and J.G. Khinast, Adsorption of heavy metal cations by organic ligands grafted on porous materials, Micropor. Mesopor. Mater. 2009, 118, 251-257.

[24] M. Alkan, G. Tekin and H. Namli. FTIR and zeta potential measurements of sepiolite treated with some organosalines. J. Micropor. Mesopor. Mater. 2005, 84, 75-83.

[25] D.M. Ginter, A.T. Bell and C.J. Radke. Zeolites in synthesis of microporous materials, Molecular Sieves. M.L Occelli and H.E Robson (eds.), Van Nostrand Reinhold, New York, 1992, Chapter 1, p 6-13.

[26] S. Mitchell, A. Bonilla and J. Pérez-Ramírez. Preparation of organic-functionalized mesoporous ZSM-5 zeolites by consecutive desilication and silanization. Mater. Chem. Phys. 2011, 127, 278-284. 
[27] M.A. Keane. The Removal of copper and nickel from aqueous solution using Y zeolite ionexchangers, Colloids and Surf. A: Physicochem. Eng. Aspects 1998, 138, 11-19.

[28] W. Mozgawa. The Influence of some heavy metal cations on the FTIR spectra of zeolites. J. Mol. Struct. 2001, 596, 129-137.

[29] A.M. Mureseanu, A. Reiss, I. Stefanescu, E. David, V. Parvulescu, G. Renard and V. Hulea. Modified SBA-15 mesoporous silica for heavy metal ions remediation, Chemosphere. 2008, 73, 1499-1504.

[30] J. Aguado, J.M. Arsuaga, A. Arencibia, M. Lindo and V. Gascón. Aqueous heavy metals removed by adsorption on amine functionalized mesoporous silica. J. Hazard. Mater. 2009, $163,213-221$.

[31] X. Bao, Z. Yan, D. Ma, J. Zhuang, X. Liu, X. Liu, X. Han, F. Chang, L. Xu and Z. Liu. On the acid dealumination of USY zeolite: a solid-state NMR investigation. J. Mol. Catal. A: Chem. 2003, 194, 153-167.

[32] T. Bein, R.F. Carver, R.D. Farlee and G.D. Stucky. Solid-state silicon- ${ }^{29}$ NMR and infrared studies of mono and polyfunctional silanes with zeolite Y surfaces. J. Am. Chem. Soc. 1988, 110, 4546-4553.

[33] M.A. Khadin and M.A. Al-Shafei. Solid-state NMR spectroscopy and refinery catalysts. Research and Development Centre, Saudi Aramco, Dhahran, 31311, Saudi Arabia.

[34] A.P.M. Alves, M.G. Fonseca and A.F. Wanderley. Inorganic-organic hybrids originating from organosilane anchored onto leached vermiculate. Materials Research. 2013, 16, 891-897.

[35] X. Wang, K.S.K. Lin, J.C.C. Chan and S. Cheng. Synthesis and catalytic application of ordered large pore aminopropyl-functionalized SBA-15 mesoporous materials. J. Phys. Chem. B, 2005, 109, 1763-1769.

[36] W. Ngeontae, W. Aeungmaitrepirom and T. Tuntulani. Chemically modified silica gel with aminothioamidoanthraquinone for solid phase extraction and pre-concentration of $\mathrm{Pb}(\mathrm{II})$, $\mathrm{Cu}(\mathrm{II}), \mathrm{Ni}(\mathrm{II}), \mathrm{Co}(\mathrm{II})$ and Cd(II). Talanta, 2007, 71, 1075-1082.

[37] P. Zong, D. Cao , S. Wang, C. He and Y. Zhao, Synthesis of $\mathrm{Fe}_{3} \mathrm{O}_{4} / \mathrm{CD}$ magnetic nanocomposite via low temperature plasma technique with high enrichment of $\mathrm{Ni}$ (II) from aqueous solution. J. Taiwan Institute of Chemical Engineers, 2017, 70, 134-140. 


\section{Figure captions}

Figure 1: Schematic representations of ligand attachment to one (a), two(b) and three(c) silicon sites on a zeolitic surface

Figure 2: PXRD pattern for zeolite $\mathrm{Y}$ with anhydrous formula $\left(\mathrm{Na}_{54.91}, \mathrm{Al}_{56} \mathrm{Si}_{136}\right)_{384}{ }^{25}$ (black experimental pattern) matched with the ICDD reference 01-070-4285 (blue vertical tick marks) ${ }^{25}$ Figure 3: FTIR spectrum of the as synthesised zeolite $Y$

Figure 4: TGA thermogram showing the weight loss and thermal behaviour of zeolite $Y$ Figure $5:{ }^{29} \mathrm{Si} \mathrm{CP}$ and DP MAS NMR spectra for zeolite Y_and APTES bonded zeolite Y Figure $6:{ }^{13} \mathrm{C} \mathrm{CP}$ and DP MAS NMR spectra for APTES bonded to zeolite $\mathrm{Y}$

Figure 7: FTIR spectrum of APTES modified zeolite Y compared to as synthesised zeolite Y

Figure 8: Thermogram of ligand grafted zeolite Y showing the stages of weight loss

Figure 9: Nickel adsorption by modified and unmodified zeolite $Y$ at varying concentrations between 0.01 to $0.1 \mathrm{M}$

Figure 10: Removal of transition metals ions by APTES modified zeolite $\mathrm{Y}$ as a function of time.

\section{Figures}
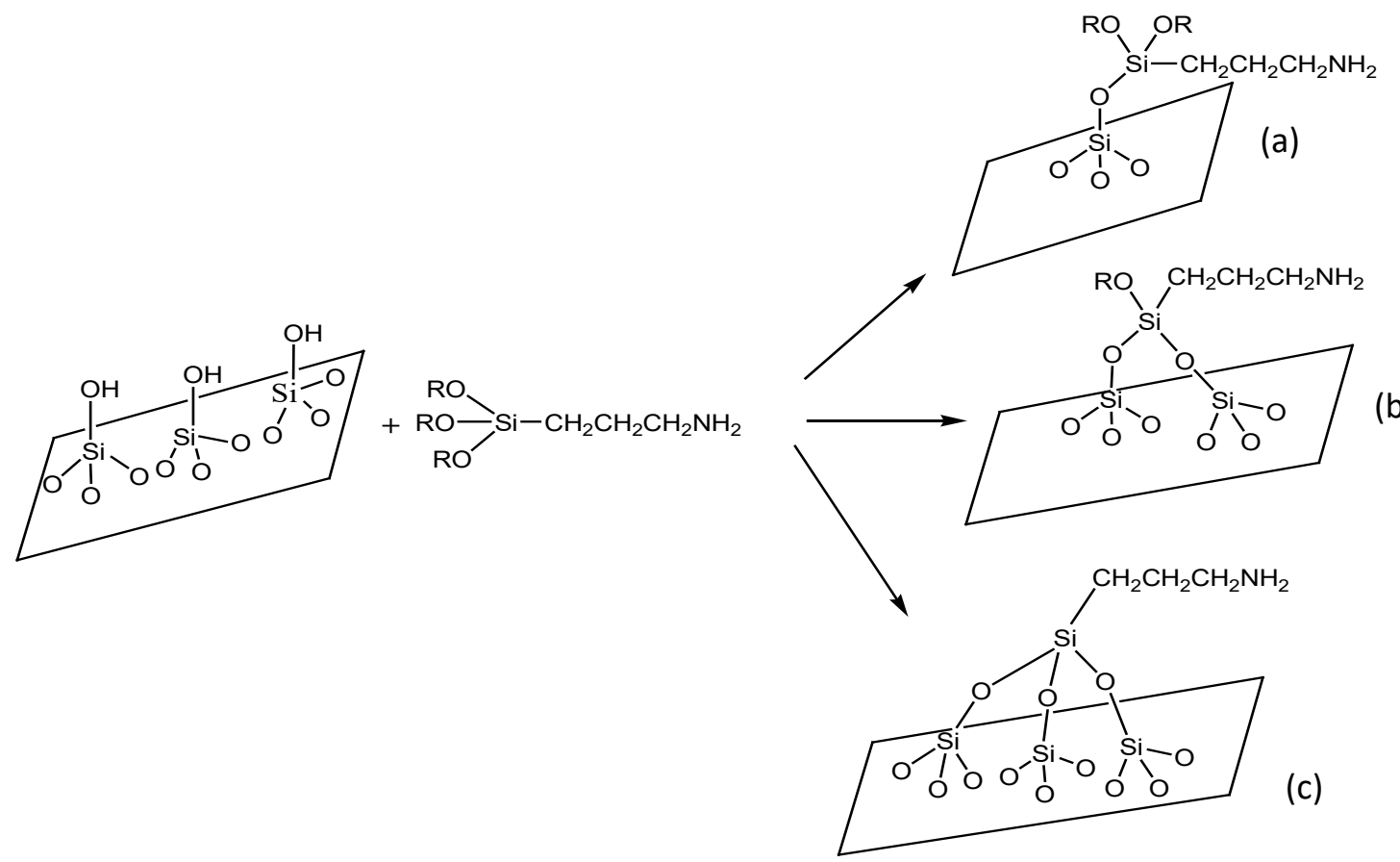

Figure 1: 


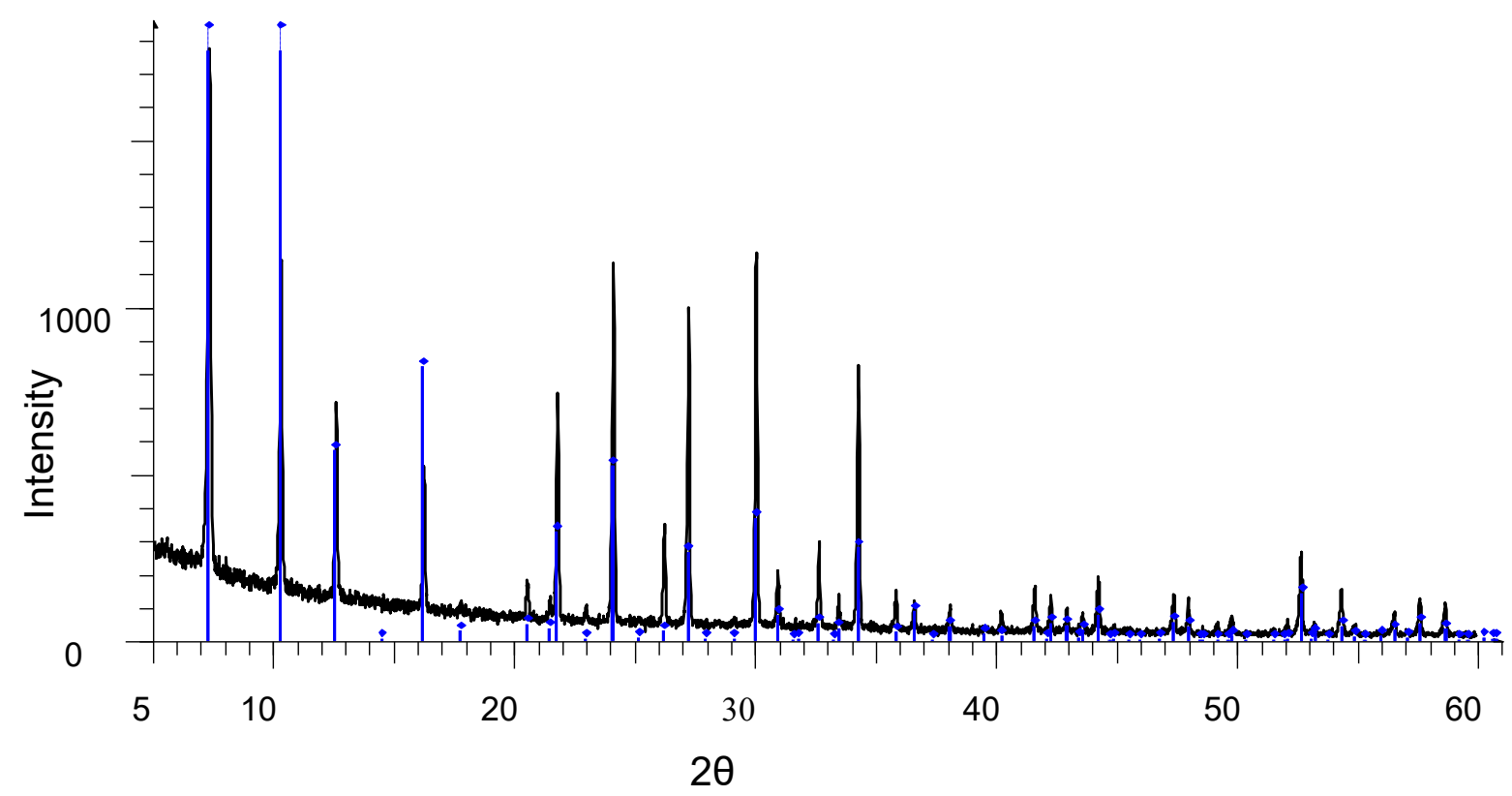

Figure 2:

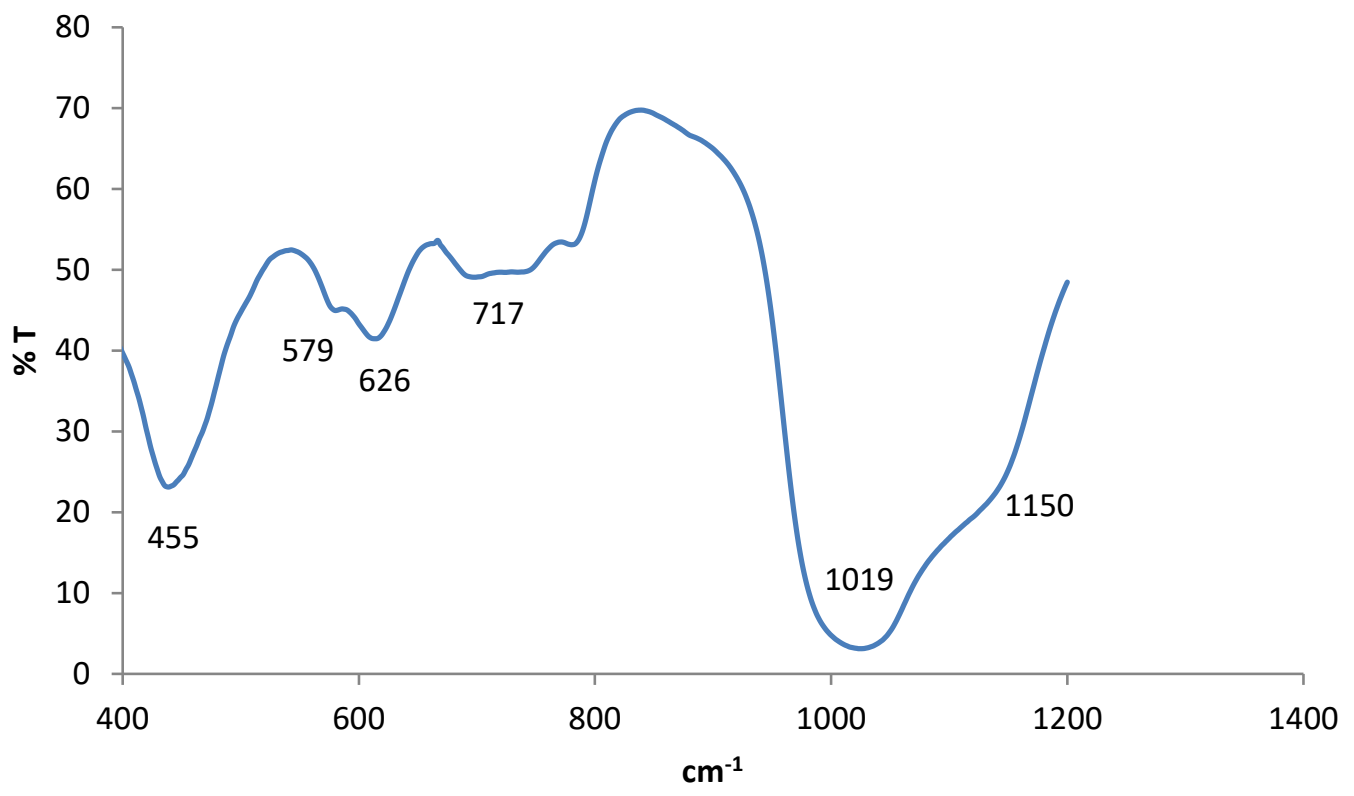

Figure 3: 


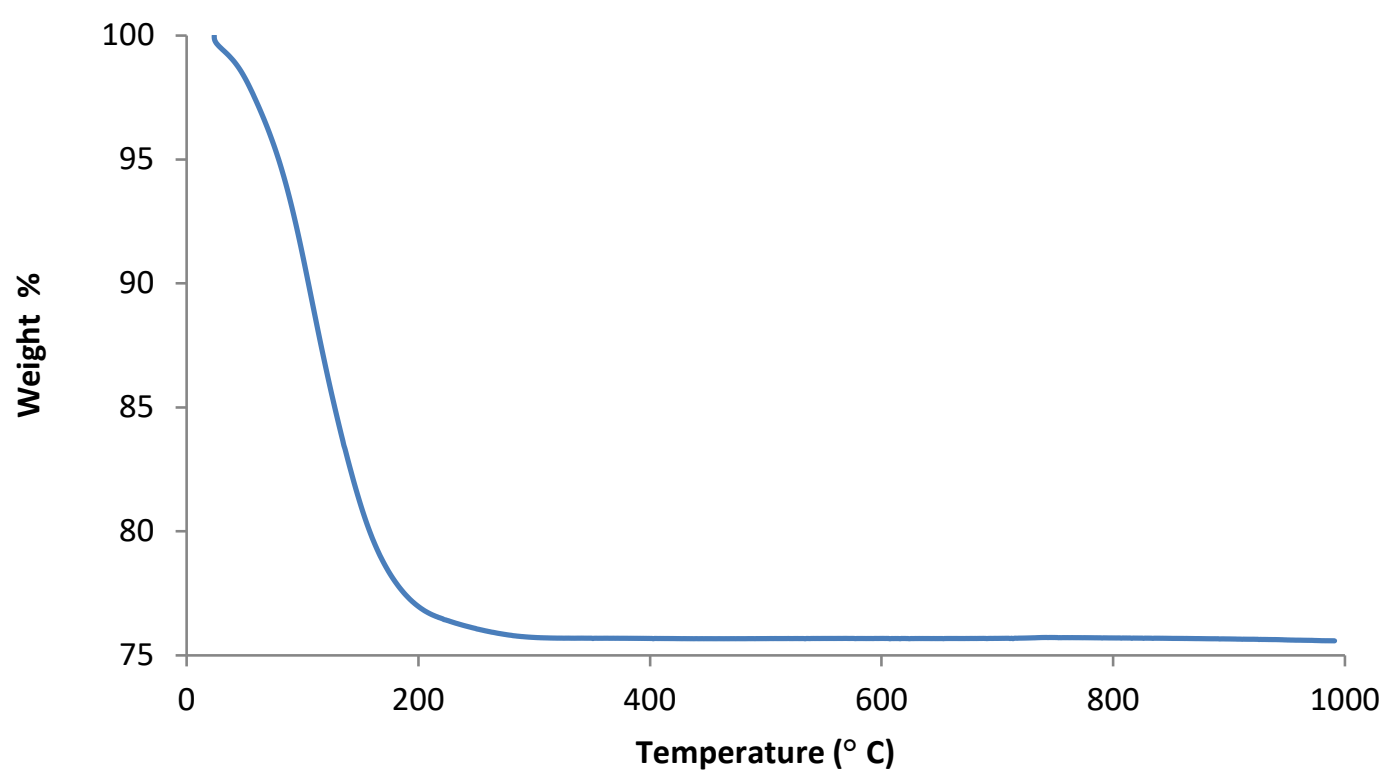

Figure 4:
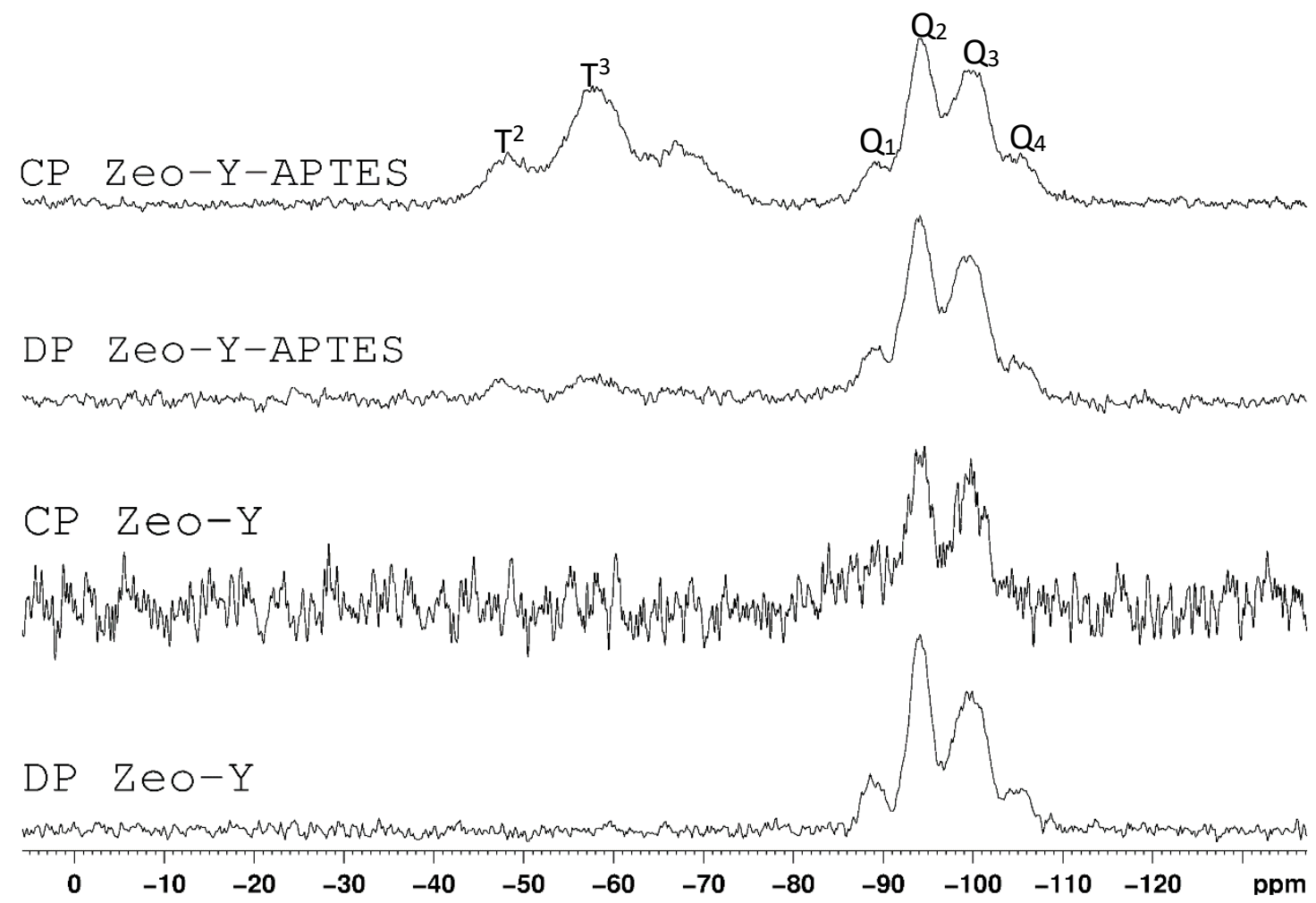

Figure 5: 


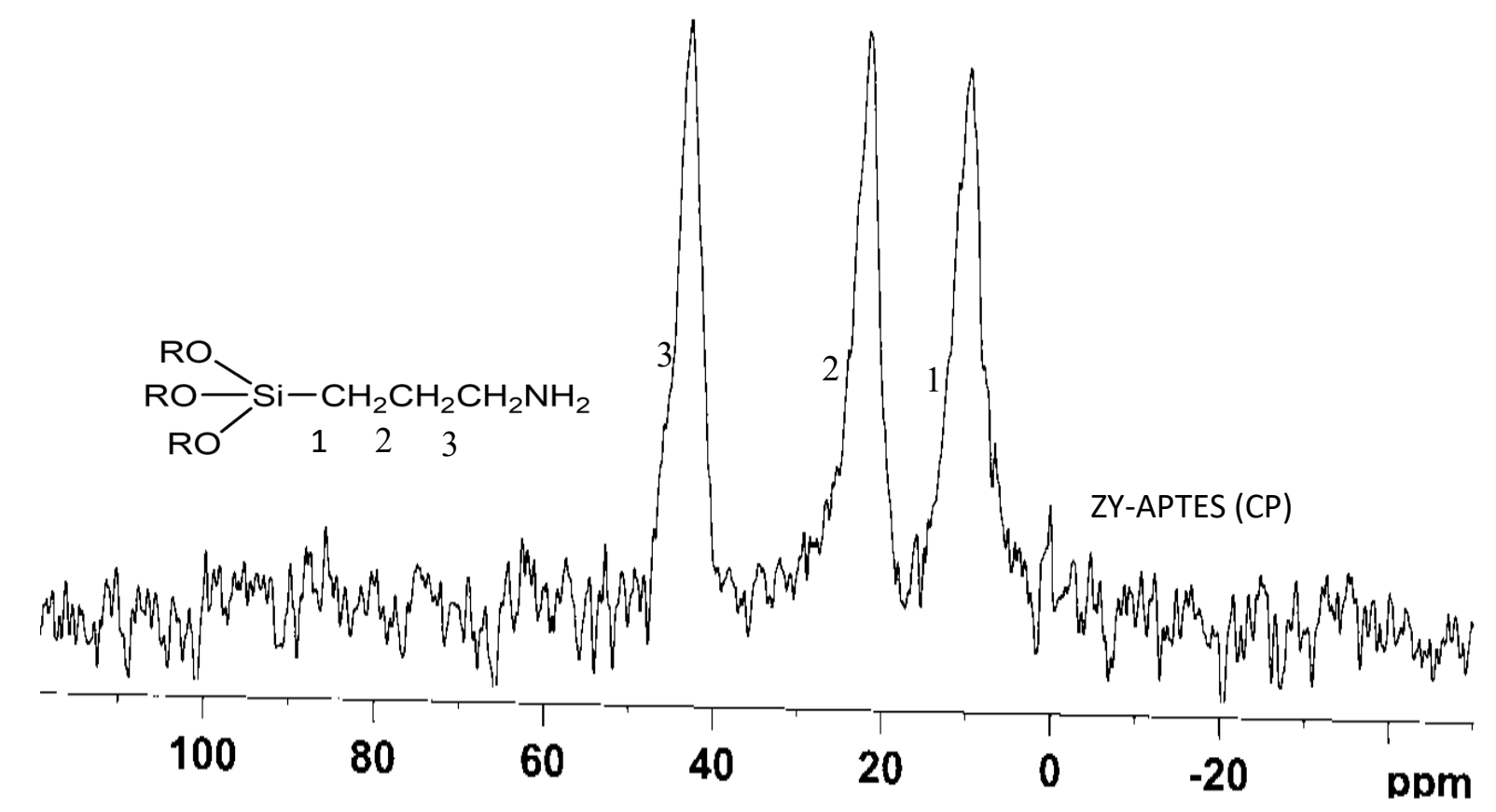

Figure 6:

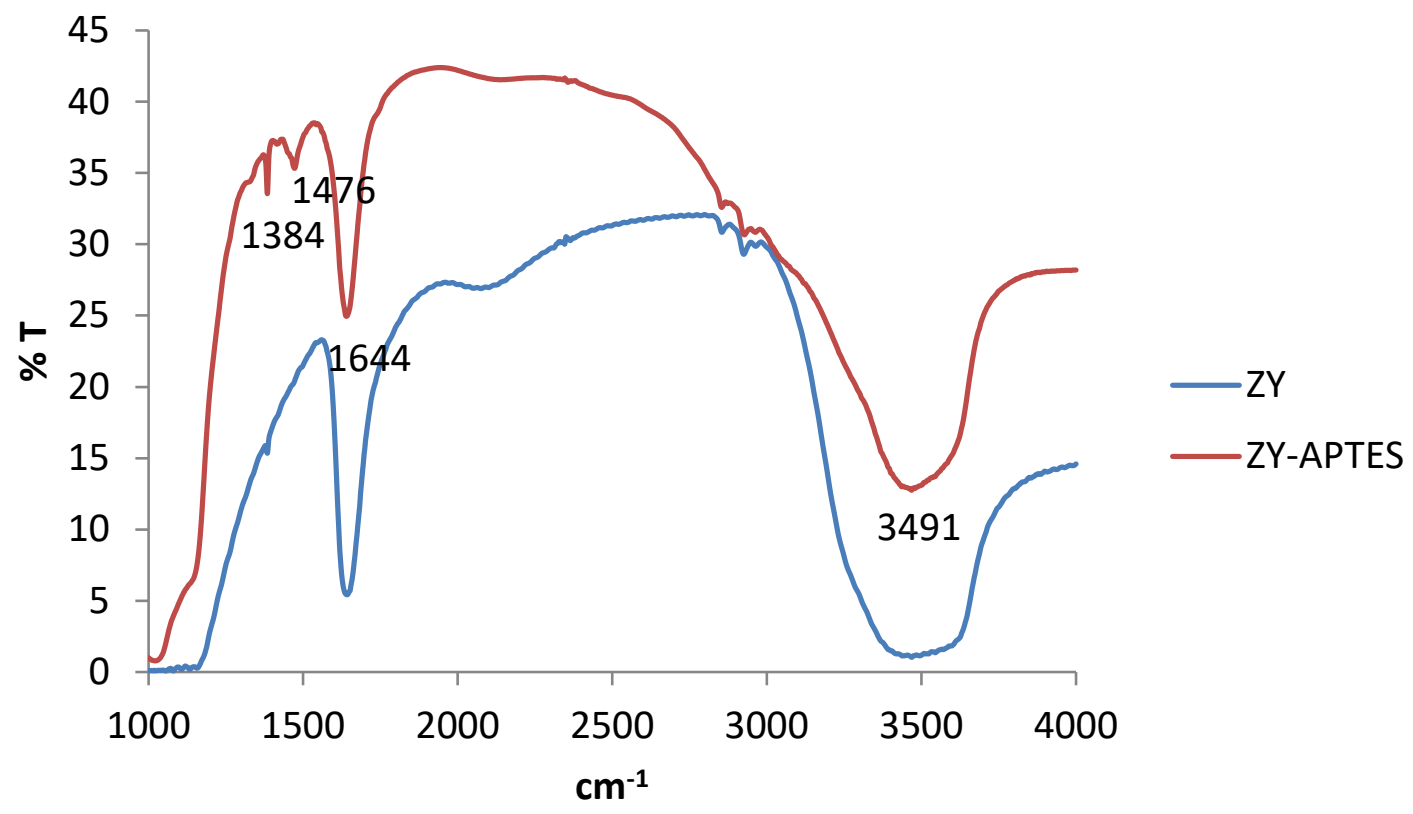

Figure 7: 


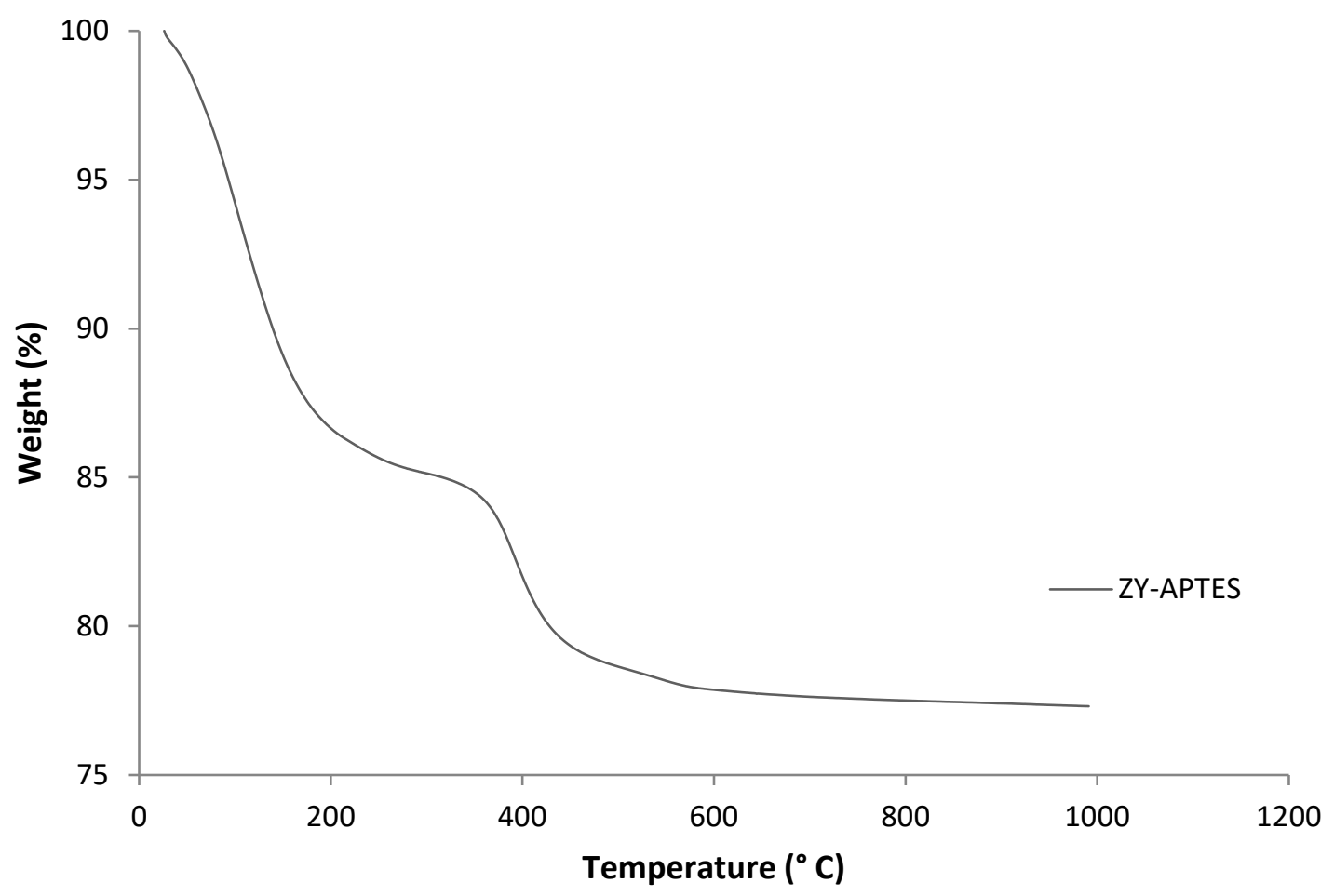

Figure 8:

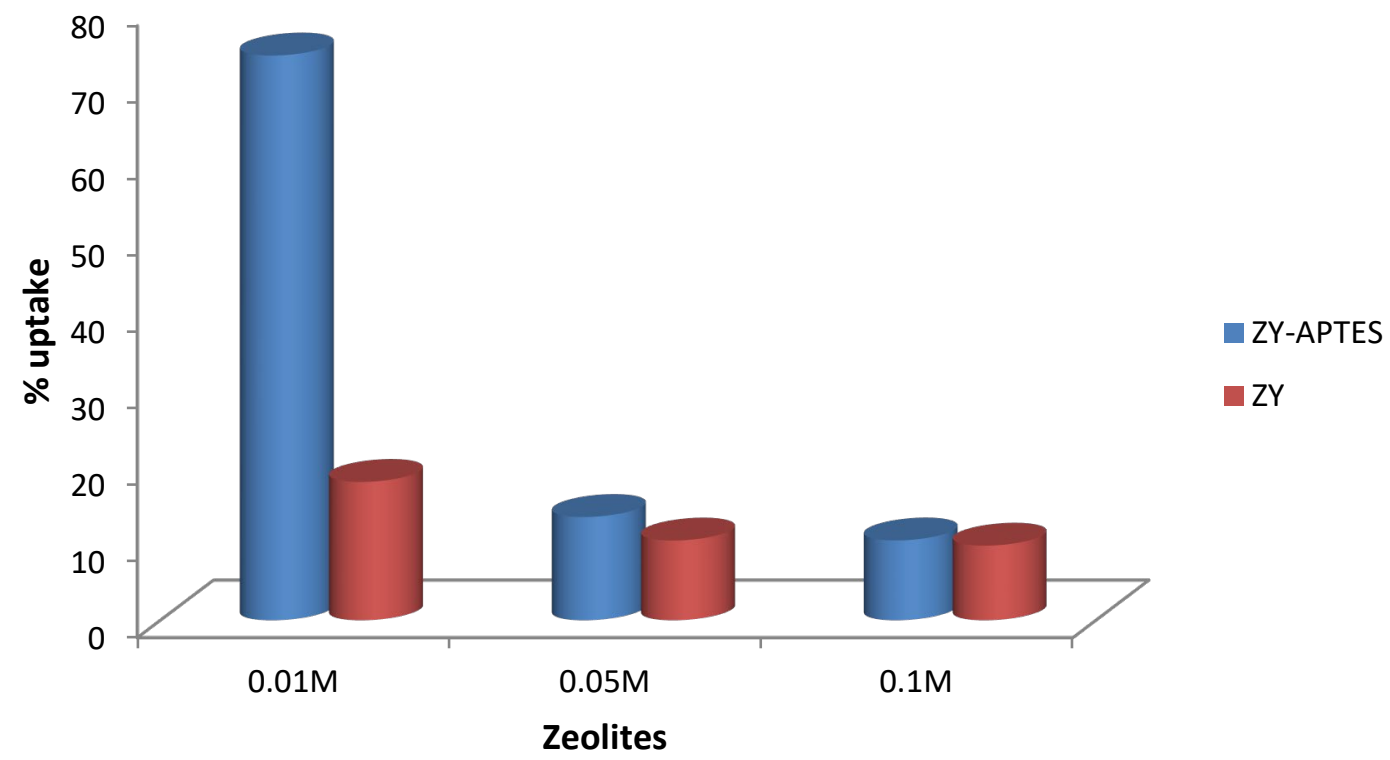

Figure 9: 


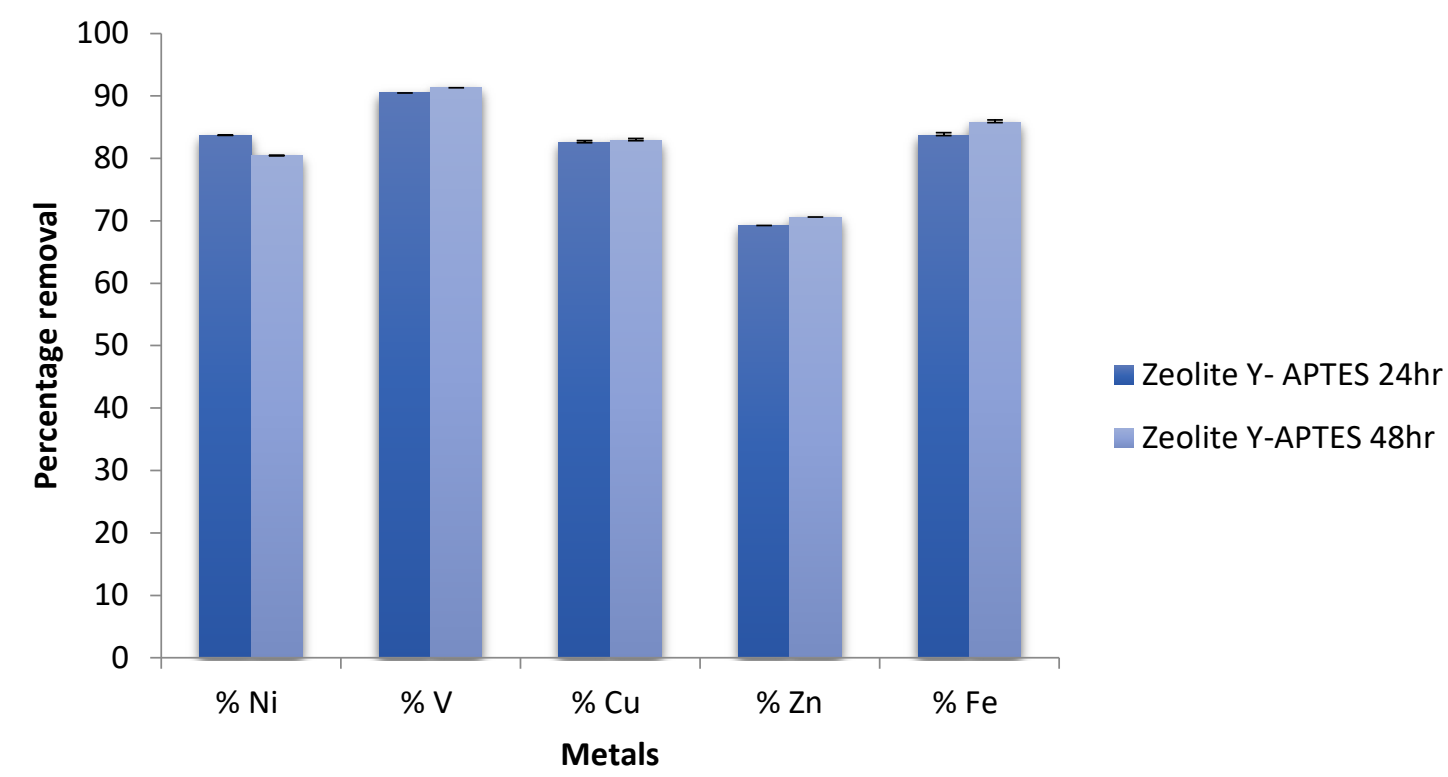

Figure 8:

\section{Table captions}

Table 1: Elemental composition of the as synthesised zeolite $\mathrm{Y}$

Table 2: Elemental analysis of the modified zeolites

Table 3: Comparison of the ligand loading and metal loading for zeolite $\mathrm{Y}$

Table 4: Original concentration of metal ions in crude oil before and after extraction

Table 5: Metal cations from heavy crude oil hydrotreatment extract 
Tables

Table 1: Elemental composition of the as synthesised zeolite $Y$

\begin{tabular}{lll}
\hline Elements & Zeolite $Y$ & \\
& Atomic \% & Wt. \% \\
\hline$O$ & 61.3 & 48.7 \\
$\mathrm{Na}$ & 8.1 & 9.2 \\
$\mathrm{Al}$ & 8.6 & 11.5 \\
$\mathrm{Si}$ & 22.0 & 30.7 \\
$\mathrm{Si} / \mathrm{Al}$ & 2.6 & 2.67 \\
\hline
\end{tabular}

Table 2: Elemental analysis of the modified zeolites

\begin{tabular}{|l|l|l|l|l|l|l|l|l|l|}
\hline Zeolite & \multicolumn{3}{|c|}{ Hexane } & \multicolumn{5}{c|}{ Toluene } & \multicolumn{3}{c|}{ Acetone } \\
\cline { 2 - 10 } & $\% \mathrm{C}$ & $\% \mathrm{H}$ & $\% \mathrm{~N}$ & $\% \mathrm{C}$ & $\% \mathrm{H}$ & $\% \mathrm{~N}$ & $\% \mathrm{C}$ & $\% \mathrm{H}$ & $\% \mathrm{~N}$ \\
\hline$Y$ & 5.08 & 2.11 & 1.82 & 4.97 & 2.24 & 1.64 & 1.52 & 1.89 & 0.00 \\
\hline
\end{tabular}


Table 3: Comparison of the ligand loading and metal loading for zeolite $Y$

\begin{tabular}{r|llll}
\hline Sample & $\begin{array}{l}\text { moles present } \\
\text { (moles) }\end{array}$ & $\begin{array}{l}\text { Ligand loading } \\
\text { (moles) }\end{array}$ & $\begin{array}{l}\text { Metal loading } \\
\text { (moles) }\end{array}$ & $\begin{array}{l}\text { Ligand/Metal } \\
\text { ratio }\end{array}$ \\
\hline Ligand-zeolite Y/0.5g & - & 0.000235 & - & - \\
$0.01 \mathrm{M} \mathrm{Ni/300mL}$ & 0.0025 & - & 0.001845 & 0.127371 \\
$0.05 \mathrm{MNi} / 300 \mathrm{~mL}$ & 0.0125 & - & 0.001663 & 0.141311 \\
$0.1 \mathrm{MNi} / 300 \mathrm{~mL}$ & 0.025 & - & 0.000019 & 12.368421 \\
\hline
\end{tabular}

Table 4: Original concentrations of metal ions in crude oil before and after extraction

\begin{tabular}{|c|c|c|c|c|c|c|c|c|c|}
\hline \multirow{2}{*}{$\begin{array}{r}\text { Crude oil samples before } \\
\text { and after metal ion } \\
\text { extraction }\end{array}$} & \multicolumn{9}{|c|}{ Metal ions concentration (ppm) } \\
\hline & $\mathbf{N i}$ & $\mathbf{F e}$ & $\mathbf{Z n}$ & $\mathbf{V}$ & $\mathrm{Cr}$ & $\mathbf{C u}$ & As & Mn & $\mathbf{P b}$ \\
\hline Crude sample & 14.06 & 15.06 & 4.67 & 0.51 & 0.49 & 0.53 & 0.6 & 0.49 & 0.22 \\
\hline Sample $+\mathrm{H}_{2} \mathrm{O}$ & 13.54 & 14.70 & 3.63 & & & & & & \\
\hline Sample $+\mathrm{H}_{3} \mathrm{PO}_{4}(0.05 \mathrm{M})$ & 10.93 & 3.59 & 2.59 & & & & & & \\
\hline Sample + EDTA $(0.05 M)$ & 9.89 & 3.23 & 1.04 & & & & & & \\
\hline Mixed crude $+I P A$ & 9.37 & 3.21 & 1.04 & & & & & & \\
\hline
\end{tabular}

Table 5: Metal cations from heavy crude oil hydrotreatment extract.

\begin{tabular}{|c|c|c|c|}
\hline \multirow[t]{2}{*}{ Extracting Media } & \multicolumn{3}{|c|}{$\%$ Extracted } \\
\hline & Ni (II) & $\mathrm{Fe}$ (II) & $\mathrm{Zn}$ (II) \\
\hline $\mathrm{H}_{2} \mathrm{O}$ & 3.70 & 2.39 & 22.27 \\
\hline $\mathrm{H}_{3} \mathrm{PO}_{4(a q .)}$ & 22.30 & 76.16 & 44.54 \\
\hline $\operatorname{EDTA}_{(a q .)}$ & 29.66 & 78.55 & 77.73 \\
\hline$I P A_{\text {(aq.) }}$ & 33.36 & 78.69 & 78.59 \\
\hline
\end{tabular}

